\title{
Lessons from management of syphilis in Nunavut, Canada, 2012-2020
}

\author{
Ameeta E Singh ${ }^{1 *}$, Kethika Kulleperuma ${ }^{2}$, Jenny Begin², Jessica DeGuzman ${ }^{3}$, Diane Sammurtok ${ }^{4}$, \\ Obed Anoee ${ }^{4}$, Theresa Koonoo' ${ }^{2}$, Jasmine Pawa ${ }^{2,5}$
}

\begin{abstract}
Background: Nunavut, part of Inuit Nunangat, is a geographically vast territory in northern Canada, with a population of over 38,000 people. Most $(85 \%)$ of the population identify as Inuit. Nunavut has experienced a significant rise in heterosexual infectious syphilis cases since 2012. Management of communicable diseases, including syphilis, is challenging due to high staff turnover and long delays in specimen transport times. Social determinants of health are also an important contributor. The aim of this study is to describe the epidemiology and program elements for infectious syphilis from 2012-2020 and to highlight beneficial interventions.

Methods: Syphilis is a notifiable disease in Nunavut with all cases reported to the Territorial Department of Health. Cases were staged by a medical consultant. Data were analyzed and released in public reports as part of the public health program.
\end{abstract}

Results: From 2012 to 2020,655 infectious syphilis cases were reported, with $53 \%$ of reported cases among females. Infection rates were highest in 20 to 39 -year-olds. There was significant variability in reported cases over this time period by geographic region, with the majority of infectious cases reported from the Kivalliq region. Despite 48 reported cases in pregnancy, no confirmed congenital syphilis cases were identified. Program staff identified strengths of the response as well as ongoing needs, such as plain language resources available in multiple languages.

Conclusion: Despite the logistical challenges with syphilis management in the territory, the overall outcomes have been positive, with no confirmed congenital cases identified. We attribute this to a coordinated effort by multiple partners including key actions by public health nurses and community health representatives.
This work is licensed under a Creative Commons Attribution 4.0 International License.

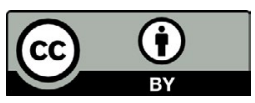

Affiliations

1 Division of Infectious Diseases, University of Alberta, Edmonton, $A B$

2 Government of Nunavut, Department of Health, Iqaluit, NU

${ }^{3}$ Government of Nunavut, Department of Health, Rankin Inlet, NU

${ }^{4}$ Government of Nunavut, Department of Health, Arviat, NU

${ }^{5}$ Dalla Lana School of Public Health, University of Toronto, Toronto, ON

\section{*Correspondence:}

ameeta@ualberta.ca

Suggested citation: Singh AE, Kulleperuma K, Begin J, DeGuzman J, Sammurtok D, Anoee O, Koonoo T, Pawa J. Lessons from management of syphilis in Nunavut, Canada, 2012-2020. Can Commun Dis Rep 2022;48(2/3):102-10. https://doi.org/10.14745/ccdr.v48i23a08

Keywords: syphilis, Canada, Arctic region, epidemiology, public health, Community Health Representative

\section{Introduction}

Nunavut, part of Inuit Nunangat, is a geographically vast northern territory in Canada with a population of over 38,000 people, of whom $85 \%$ identify as Inuit (1). Nunavut has experienced a significant rise in heterosexual infectious syphilis cases over the last few years. Prior to 2012 , five or fewer cases per year were identified; in 2016-2018, more than 100 cases per year were identified; far higher than the national rate. In 2017, the Department of Health contracted an infectious diseases specialist to assist with the outbreak. Following a 2017 review of syphilis prevention and control in the territory, several changes were made to the syphilis program in Nunavut including the revision of territorial syphilis guidelines, additional training for healthcare and public health staff, enhanced prevention activities by community health representatives (CHR) and staging and assistance with management and follow-up of all syphilis cases by the medical consultant. Since many pregnant women are transferred out of territory (especially from the Kivalliq region) for delivery, the medical consultant has endeavoured to prepare summary letters on all cases with positive syphilis serology to facilitate care in the receiving province. 
Syphilis management in Nunavut is particularly challenging for several reasons, including the vast geographic area with triage of cases requiring complex care to three different provinces in Canada, the remote locations of many communities resulting in long delays in specimen transport times and inconsistent staffing. Social determinants of health are relevant not only to syphilis but to the overall health status of Inuit. Work by Inuit Tapiriit Kanatami, Canada's National Inuit Organization, flagged the importance of self-determination and of building on the strengths of Inuit culture and language (2). Despite these challenges, through the efforts of community members and health staff, we have not observed some of the adverse outcomes reported in other jurisdictions, such as higher rates of congenital syphilis cases.

Our objective was to describe the epidemiology of infectious syphilis in Nunavut and to describe the factors that may have contributed to the observed outcomes. This work is conducted and shared as part of public health practice, including program planning and evaluation, not as formal research.

\section{Methods}

\section{Healthcare infrastructure and flow}

A variety of public governmental, non-governmental resources and published literature were accessed to describe the flow of healthcare and public health services in Nunavut and to outline the roles and responsibilities of health personnel in Nunavut.

\section{Syphilis testing}

Similar to other Canadian jurisdictions, symptomatic persons access diagnostic services while asymptomatic individuals may be offered syphilis testing as a part of screening or case finding (via contact tracing and notification) processes. Syphilis is a notifiable disease in Nunavut, with all cases reported to the territorial Department of Health. Serologic tests are used to diagnose syphilis in Nunavut using a reverse sequence algorithm. The initial screen is with a syphilis enzyme immunoassay (Architect Syphilis TP Chemiluminescent Microparticle Immunoassay, Abbot Laboratories, Abbott Park, Illinois, United States). A positive enzyme immunoassay is followed by a quantitative rapid plasma reagin (RPR BD Macro-Vue ${ }^{T M}$ RPR test, Becton Dickinson Microbiology Systems, Mississauga, Ontario, Canada) and the first time a syphilis enzyme immunoassay is positive, it is confirmed using a Treponema pallidum particle agglutination assay (TPPA; Serodia ${ }^{\circledR}$-TPPA, Fujirebio Diagnostics Inc, Seguin, Texas, United States). Syphilis is treated as per the Nunavut sexually transmitted infection treatment guidelines (3) and positive results are reported to local, territorial and national public health authorities as per the territorial notifiable disease guidelines (3).

\section{Case reporting and classification}

All cases of syphilis in Nunavut are reported by healthcare providers to the Regional Communicable Disease Coordinator (RCDC) and territorial epidemiology team using a standardized case definition form. The following information is routinely entered into a surveillance database: name; date of birth; sex; geographic region; healthcare number; reason for testing; ethnicity; details on prior syphilis history; pregnancy status; results of syphilis laboratory tests; treatment provided date; and staging. Although routinely collected on the case definition form, the following information is not routinely entered into the database: presence or absence of symptoms; risk factors; and partner information. Completed forms were sent to a medical consultant over the study period and staging was completed using Nunavut Case Definitions (see Supplemental Table: Nunavut Surveillance Case Definitions for Syphilis) (3). Confirmation of case staging is then returned to the RCDC and territorial epidemiologist, who work closely with the Territorial Communicable Disease Specialists (TCDS) and Public Health Officers as required. Contact tracing and other public health preventive measures are conducted as per territorial guidelines.

\section{Data collection and analysis}

National and territorial infectious syphilis case counts are extracted from the national notifiable disease dataset and territory's syphilis surveillance database, respectively. National and Nunavut regional population data is extracted from Statistics Canada (4) and Nunavut Bureau of Statistics, respectively. All rates are standardized using the 2011 standard population. Data are analyzed using Microsoft Excel and released in public reports as part of the public health program.

\section{Results}

\section{Healthcare infrastructure and flow of services} Syphilis diagnosis, management and prevention: The roles and responsibilities of the range of health personnel who provide clinical and preventive services for persons potentially affected or infected with syphilis in Nunavut are summarized in Table 1. Nunavut's healthcare system relies heavily on shorter-term nursing contracts and locum physicians, many of whom come from outside the territory (5). Of 25 communities in the territory, three (lqaluit, Cambridge Bay and Rankin Inlet) have full-time physicians while smaller communities are typically serviced by physicians on a rotating basis (5). For most communities, twenty-two community-based clinics, staffed primarily by community health nurses (CHNs) (registered nurses working in an expanded scope of practice), offer primary care and acute services (5). Locum staff typically stay for relatively short periods and turnover of both physicians and nurses is very high with the vacancy rate in some regions is as high as $71 \%$ (3). Through this process, medical directives for $\mathrm{CHNs}$ and public health nurses (PHNs) were reviewed for opportunities to better share work. 
Table 1: Roles and responsibilities of healthcare staff providing prevention and care for persons potentially affected by or infected with syphilis ${ }^{\mathrm{a}}$

\begin{tabular}{|c|c|}
\hline Type of provider & Roles \\
\hline $\begin{array}{l}\text { Most responsible } \\
\text { provider (e.g. } \\
\text { registered nurse, } \\
\text { medical doctor, } \\
\text { midwife) }\end{array}$ & $\begin{array}{l}\text { Assess individual } \\
\text { Conduct testing } \\
\text { Provide treatment } \\
\text { Complete Syphilis Report Form or Syphilis } \\
\text { Report Form for infants and STI Contact } \\
\text { Investigation form and submit to RCDC } \\
\text { Notify, assess and treat contacts }\end{array}$ \\
\hline Public health nurse & $\begin{array}{l}\text { Assess patient } \\
\text { Conduct testing } \\
\text { Arrange treatment } \\
\text { Coordinate partner notification }\end{array}$ \\
\hline $\begin{array}{l}\text { Regional } \\
\text { Communicable } \\
\text { Disease Control } \\
\text { nurse }\end{array}$ & $\begin{array}{l}\text { Receive and monitor positive test results and } \\
\text { follow-up serology for syphilis } \\
\text { Receive Syphilis Notification Forms from MRP } \\
\text { Ensure syphilis treatment and follow-up } \\
\text { completed by MRP } \\
\text { Coordinate transfer of medical information/ } \\
\text { recommendations to MRP } \\
\text { Consult with STI Medical Consultant as needed } \\
\text { for management of cases } \\
\text { Ensure syphilis staging completed by STI } \\
\text { Medical Consultant and submitted to TCDS } \\
\text { and epidemiologist }\end{array}$ \\
\hline $\begin{array}{l}\text { Community Health } \\
\text { Representative }\end{array}$ & $\begin{array}{l}\text { Promotes health and wellbeing in the } \\
\text { community by responding to community public } \\
\text { health needs and supporting regional and } \\
\text { territorial public health priorities by assisting } \\
\text { individuals to develop skills and knowledge } \\
\text { through providing public health information } \\
\text { and education for heath }\end{array}$ \\
\hline $\begin{array}{l}\text { Territorial STI } \\
\text { Medical Consultant }\end{array}$ & $\begin{array}{l}\text { Providing expert clinical advice and support } \\
\text { to the Department of Health and individual } \\
\text { practitioners regarding the management of } \\
\text { STIs, especially syphilis including: } \\
\text { Staging, treatment and follow-up } \\
\text { Support for the territorial communicable } \\
\text { disease program on the topic of STIs and } \\
\text { controlling the syphilis outbreak } \\
\text { Consultation on difficult or complicated syphilis } \\
\text { cases } \\
\text { Developing consultation letters for prenatal } \\
\text { women diagnosed with syphilis } \\
\text { Consultation and recommendations for follow- } \\
\text { up of the infants born to syphilis positive } \\
\text { mothers }\end{array}$ \\
\hline Epidemiologist & $\begin{array}{l}\text { Analyses and interprets syphilis data } \\
\text { Develops reports }\end{array}$ \\
\hline $\begin{array}{l}\text { Territorial } \\
\text { Communicable } \\
\text { Disease Specialist }\end{array}$ & $\begin{array}{l}\text { Coordinate out of province transfer of } \\
\text { information for cases and contacts } \\
\text { Works with } \mathrm{MOH} / \mathrm{PHOs} \text { on territorial } \\
\text { protocols }\end{array}$ \\
\hline
\end{tabular}

Table 1: Roles and responsibilities of healthcare staff providing prevention and care for persons potentially affected by or infected with syphilis ${ }^{\mathrm{a}}$ (continued)

\section{Type of provider Roles}

Medical Officer of Health(s)/Public Health Officer(s)

Provides public health expertise to support the key operations of health protection, disease prevention and health promotion

Provides leadership and expertise to the public health unit, including health protection and the population health unit

Establishes and maintains public health standards and best practices as well as advocates for the preservation and improvement of the health of Nunavummiut

Abbreviations: $\mathrm{MOH}$, Medical Officer of Health(s); MRP, Most Responsible Provider PHN, public health nurses; PHO, Public Health Officer(s); RCDC, Regional Communicable Disease Coordinator; STI, sexually transmitted infection; TCDS, Territorial Communicable Disease Specialists

a This summary is focused on the care for syphilis and that there are many who work in health system roles who are not acknowledged here. This includes, but is not limited to, administrative staff; medical travel programs; policy, finance, communications and human resources team members

Community health representatives are invaluable members of the health services team (5). They have important expertise and experience in understanding the communities they work in, including being able to work in and connect with individuals in Inuktitut. A federal CHR program was implemented in 1962 by the Medical Services Branch of Health and Welfare Canada (6). Within the territorial Department of Health for Nunavut, there currently 33 available positions with 27 full-time CHRs, of whom all but two are female. While the principal role of the CHR in recent years has been to focus on health education, promotion and infection prevention, the specific role varies from community to community. In Nunavut, CHRs have been mobilized to assist with the response to syphilis since the start of the outbreak. Specific activities have included hosting information sessions at high schools, providing access to condoms and information regarding birth control options and developing health promotion materials. Other activities have included hosting health information booths, assisting with translation services and providing support in navigating the health system. In some communities, hosting monthly radio shows has facilitated the provision of information and allowed community members to phone in and ask questions.

Persons requiring additional medical services are typically transported out of territory, sometimes via another in-territory location, as summarized in Figure 1.

Syphilis testing: Specimens from the Kitikmeot region were submitted to DynaLife Laboratories (Edmonton, Alberta) and from the Qikiqtaaluk and Kivalliq regions to the Qikiqtani General Hospital Laboratory (Iqaluit, Nunavut). Since transport from remote communities only occur on certain days of the week depending on flight schedules and may require a transfer of specimens at another in-territory hub, the time to test results can be very prolonged. In smaller communities, the time to 
Figure 1: Examples of patterns of patient travel from Nunavut to out of territory destinations ${ }^{a}$

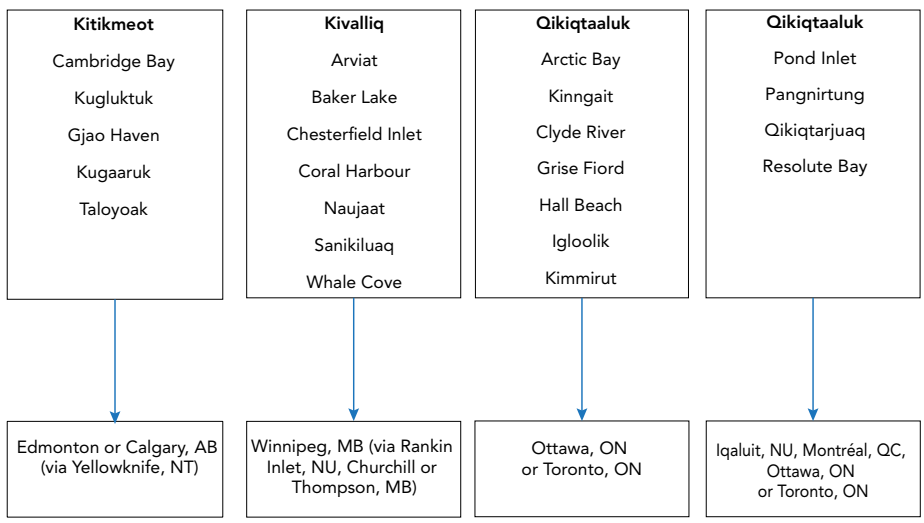

Abbreviations: AB, Alberta; MB, Manitoba; NU, Nunavut; NT, Northwest Territory; ON, Ontario; QC, Québec

See reference (7)

Note: The above is not an exhaustive list of communities in Nunavut but provides examples of travel patterns. It is also important to note that the community names may be out of date (for example Kinngait was formerly known as Cape Dorset)

syphilis test results often varies from 8-12 days and can be up to a few weeks. In addition, pregnant women who required transport outside of territory were often tested or re-tested in the receiving province resulting in a variability in test results, especially the RPR, due to differences in testing algorithms and types of tests used.

\section{Epidemiology}

A total of 655 cases were reported in Nunavut from 2012-2020, with $95 \%$ of reported cases among persons of Inuit ethnicity (similar to the general population with $85 \%$ identifying as Inuit). The age-standardized rates of infectious syphilis by sex in Nunavut and Canada (Figure 2) show territorial rates well above the national rates for both males and females. In contrast to the national rates, where age-standardized rates were much higher among males, the territorial age-standardized rates were similar for males and females. Figure 3 shows the age-standardized rates of infectious syphilis in Nunavut by region and year and highlight the geographic spread and relative case growth across the territory and the three regions. Since there were five or fewer annual cases reported before 2012, with the observation of increased infectious cases in 2012 (more than 20 cases), the outbreak was declared in 2012 with cases first reported in Iqaluit (Figure 4). Initially the outbreak was centered in the Qikiqtaaluk region and then shifted to the Kivalliq region. Since new infectious cases continue to be observed, the outbreak is currently considered to be ongoing. Qikiqtaaluk had more than $50 \%$ of the total Nunavut population and has been reporting cases since 2012, with notable fluctuations over time. Case growth is Kivalliq region increased dramatically in 2016 but appeared to be declining since then. Overall, 53\% $(n=349)$ of cases were reported among females with the overall male-to-female ratio in Nunavut of 0.9 (range 0.7-1.0) (Table 2). The staging of cases was classified as primary in $54 \%(n=356)$, secondary in $18 \%(n=117)$, early latent in $27 \%(n=175)$ and unknown in $1 \%(n=7)$.
Figure 2: Age-standardized rates of infectious syphilis by sex in Nunavut and Canada, 2012-2020

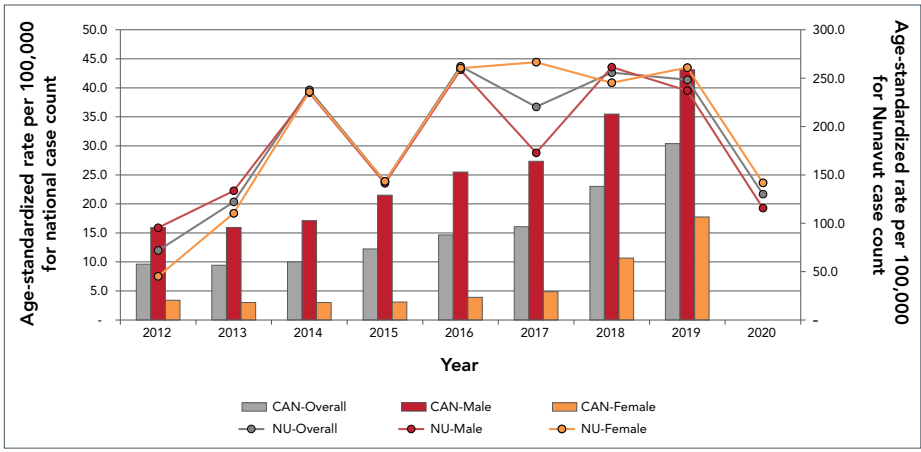

Abbreviations: CAN, Canadian; NU, Nunavut

Figure 3: Age-standardized rates of infectious syphilis in Nunavut by region and year, 2012-2020 $(n=655)$

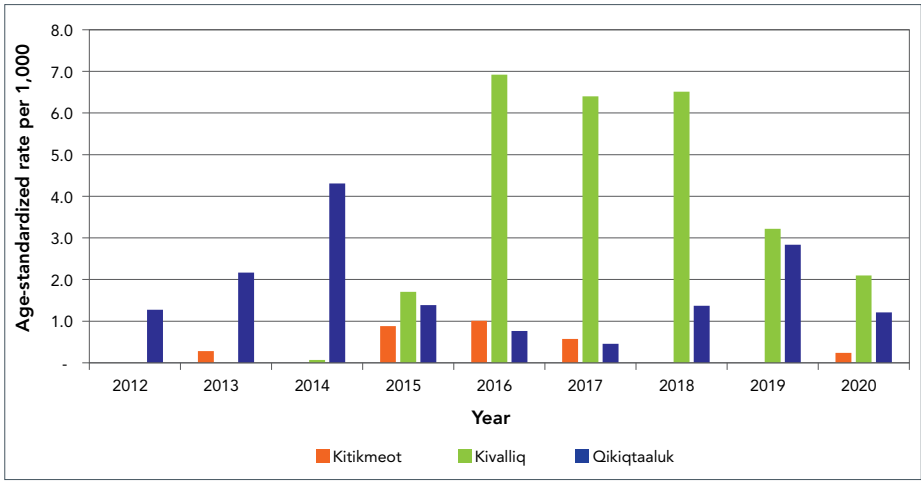

Figure 4: Epidemiological curve of infectious syphilis in Nunavut by region, 2011-2020

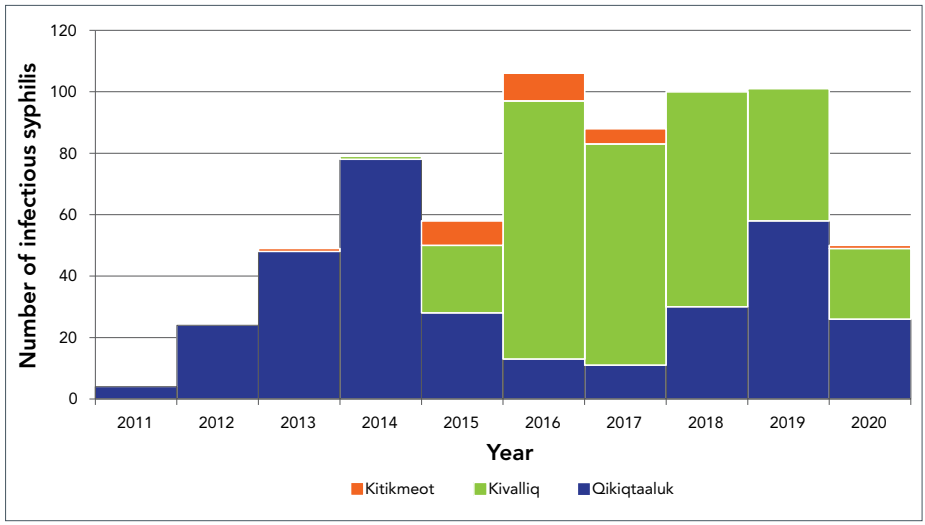

Cases were distributed across all age groups with the majority of cases between 20 and 39 years of age. During this time, 48 pregnant women were diagnosed with infectious syphilis in Nunavut, with over $66 \%$ cases in the Kivalliq region, over $30 \%$ in the Qikiqtaaluk region and fewer than $5 \%$ in Kitikmeot region (exact case counts are not available due to low reported numbers). All pregnant women were treated in accordance with Nunavut guidelines (3). With regards to neonatal outcomes, 40 of the infants were classified as non-cases (maternal transfer of antibodies only), four were either therapeutic/ 
Table 2: Infectious syphilis cases ${ }^{\mathrm{a}}$ in Nunavut by year, sex, male-to-female ratio, age group, syphilis stage and region, 2012-2020

\begin{tabular}{|l|r|r|r|r|}
\hline \multirow{2}{*}{ Description } & \multicolumn{4}{|c|}{ Region } \\
\cline { 2 - 5 } $\begin{array}{l}\text { Total case } \\
\text { count }\end{array}$ & 655 & 24 & 315 & 316 \\
\hline 2012 & 24 & 0 & 0 & 24 \\
\hline 2013 & 49 & $<5$ & $<5$ & 48 \\
\hline 2014 & 79 & $<5$ & $<5$ & 78 \\
\hline 2015 & 58 & 8 & 22 & 28 \\
\hline 2016 & 106 & 9 & 84 & 13 \\
\hline 2017 & 88 & 5 & 72 & 11 \\
\hline 2018 & 100 & 0 & 70 & 30 \\
\hline 2019 & 101 & 0 & 43 & 58 \\
\hline 2020 & 50 & $<5$ & $20+$ & 26 \\
\hline
\end{tabular}

Sex

\begin{tabular}{|l|r|r|r|r|}
\hline Female & $349(53 \%)$ & 14 & 176 & 159 \\
\hline Male & $306(47 \%)$ & 10 & 139 & 157 \\
\hline $\begin{array}{l}\text { Male-to-female } \\
\text { ratio }\end{array}$ & 0.9 & 0.7 & 0.8 & 1.0 \\
\hline 2012 & 1.7 & 0 & 0 & 0.6 \\
\hline 2013 & 1.2 & $<5$ & $<5$ & 0.8 \\
\hline 2014 & 0.8 & $<5$ & $<5$ & 1.2 \\
\hline 2015 & 0.9 & 1.7 & 0.8 & 1.2 \\
\hline 2016 & 0.9 & 0.8 & 1.4 & 0.4 \\
\hline 2017 & 0.6 & 4.0 & 1.8 & 0.8 \\
\hline 2018 & 1.0 & 0 & 1.1 & 0.9 \\
\hline 2019 & 0.9 & 0 & 0.8 & 1.3 \\
\hline 2020 & 0.7 & $<5$ & 1.9 & 1.4 \\
\hline
\end{tabular}

\section{Age group}

\begin{tabular}{|l|r|r|r|r|}
\hline $\begin{array}{l}\text { Younger than } \\
15 \text { years }\end{array}$ & $5(1 \%)$ & $<5$ & $<5$ & $<5$ \\
\hline $15-19$ years & $92(17 \%)$ & 7 & 65 & 38 \\
\hline $20-24$ years & $110(22 \%)$ & 5 & 89 & 49 \\
\hline $25-29$ years & $143(22 \%)$ & 9 & 59 & 79 \\
\hline $30-39$ years & $147(24 \%)$ & $<5$ & 64 & 93 \\
\hline 40 and older & $158(14 \%)$ & $<5$ & 35 & 55 \\
\hline
\end{tabular}

\section{Staging}

\begin{tabular}{|l|r|r|r|r|}
\hline Primary & $356(54 \%)$ & 13 & 178 & 165 \\
\hline Secondary & $117(18 \%)$ & $<5$ & 49 & 64 \\
\hline Early latent & $175(27 \%)$ & 7 & 88 & 80 \\
\hline $\begin{array}{l}\text { Documentation } \\
\text { error }\end{array}$ & $7(1 \%)$ & 0 & 0 & 0 \\
\hline
\end{tabular}

${ }^{a}$ Case counts fewer than five were not reported spontaneousabortion or stillbirth (not due to syphilis), three cases of probable congenital syphilis cases and one case was awaiting follow-up information at the time of writing. Of the cases classified as maternal transfer, 23 (57\%) of the pregnant women were treated before 20 weeks gestation and four (10\%) after 30 weeks gestation.

\section{Discussion}

After observing little or no endemic transmission of syphilis, Nunavut has experienced a significant rise in infectious syphilis cases since 2012, with numbers/rates peaking in 2016 and remaining stable each year until 2019. This increase was followed by a decline in 2020. The reason for the observed decline in 2020 was not clear as syphilis testing data were not available for the observed time period, but numbers/rate are anticipated to have declined due to reduced interactions with the healthcare system in the territory related to the coronavirus disease 2019 (COVID-19) pandemic. Similar trends were reported in other jurisdictions (8). Another possible explanation is that the prevention measures enacted during the COVID-19 pandemic, such as stay-at-home recommendations and closing of non-essential businesses, may have resulted in a change in sexual behaviour related to physical distancing and therefore a true decline in cases (8).

The outbreak of infectious syphilis was principally transmitted heterosexually in contrast to the overall Canadian rate, which is higher among males. Consequently, 48 pregnant women were diagnosed with infectious syphilis during the study period, with approximately $2 / 3$ from the Kivalliq region. The women with infectious syphilis during pregnancy from the Kivalliq region were typically flown to Winnipeg at 34-36 weeks gestation and remained there until delivery. Most of the pregnant women from the Kivalliq region were from very small communities (fewer than 2,000 individuals) that may have a small community health centre with variable levels of medical staff support and services. The main hub, Rankin Inlet, has a birthing centre with midwives who provide support for uncomplicated deliveries but since infants born to mothers treated for infectious syphilis during pregnancy require assessment for congenital syphilis by experienced paediatricians, all these women were transferred to Winnipeg for delivery. In addition, the birthing centre in Rankin Inlet is presently closed due to staffing considerations. Women who were diagnosed with infectious syphilis after 20 weeks gestation were transferred to Winnipeg for monitoring as treatment may result in a Jarisch Herxheimer reaction, which can result in the premature onset of labour (9). Pregnant women in the Qikiqtaaluk region are routinely transferred to Qikiqtani General Hospital for treatment (at greater than 20 weeks gestation) and delivery. Interestingly, two recent retrospective case series of pregnant women diagnosed with syphilis and treated in Winnipeg and Alberta reported no serious maternal 
or fetal events following treatment $(10,11)$. Nunavut medical travel accounts for $20 \%$ of health expenditures in Nunavut due to the relative absence of roads and the reliance on air travel (7); this is relevant in the context of pregnant women $>20$ weeks gestation with infectious syphilis who are routinely transferred to a major centre for treatment. The Winnipeg and Alberta studies, while small, do not support the routine practice of admission to hospital for treatment of infectious syphilis in late pregnancy. Given the small retrospective nature of the studies, however, these studies may not have identified a subset of women who may be at risk for serious adverse events.

With regards to the neonatal outcomes of infectious syphilis in pregnancy, we found no cases of confirmed congenital syphilis. Vertical transmission of syphilis occurs in all stages of syphilis and in each trimester of pregnancy, but risk of transmission increases with earlier syphilis stage and later gestational age (9). Fetal infection occurs in more than $50 \%$ of untreated early syphilis (9). The low rate of adverse neonatal outcomes observed in Nunavut can be attributed to multiple factors including the routine testing of all/majority pregnant women for syphilis in the early pregnancy and prompt treatment if syphilis is diagnosed. The majority (or perhaps all) of the women undergo syphilis testing, often in early pregnancy, due to the small size of the communities and also the women will typically access services as they usually require transfer out of most communities for delivery. Studies have consistently shown that early and adequate maternal treatment during early pregnancy confers the lowest rates of congenital syphilis and adverse pregnancy outcomes $(12,13)$. In addition, Nunavut syphilis guidelines recommend routine re-screening for infectious syphilis at 24-28 weeks gestation, thus enabling the earlier identification and treatment of reinfection. In addition, to minimize the impact of the laboratory variation in RPR results, all infectious syphilis cases returning from out of territory have a repeat RPR collected upon return so that this result can be used to inform future follow-up.

All members of the health services team play important roles in the care and prevention of persons with syphilis. While front line providers (such as $\mathrm{CHNs}$ ) are critical in doing the initial assessments and coordinating treatment, the RCDC is essential in ensuring that the treatment and serologic follow-up occur and that partner(s) are contacted and offered testing and treatment. The RCDC, in consultation with the territorial syphilis medical consultant, also ensures that relevant medical information is relayed to other providers who may be involved in the care of the patient. The TCDS consultant (who is often also a nurse) ensures that relevant information is relayed for clients for out-of-territory care and follow-up, and works with the Medical Officer of Health(s)/Public Health Officer(s) on territorial protocols. The territorial epidemiologists' role is to provide accurate and timely epidemiologic data, which is essential for program planning. Nunavut has experienced a high turnover of both permanent and locum temporary health services staff over the years and this has been particularly challenging during the syphilis surge and the COVID-19 pandemic. The update of Nunavut syphilis guidelines, one-page algorithms and protocols has helped with to ease these transitions.

The role of the CHRs cannot be underestimated. To quote the Royal Commission on Aboriginal Peoples: "One of the most successful programs involving Aboriginal people in promoting health of Aboriginal people is the community health representative program" (14). In many northern and isolated communities including in Nunavut, the turnover of health professionals, is extremely high; the CHR provides the only continuity of care in some communities. "The CHRs are the people that the community members trust and relate to in terms of health information and services." (14). There is a paucity of data in Canada on the impact of the role of CHRs in the prevention and control of communicable diseases, including syphilis. Perhaps the closest analogy in the published literature is the impact of the role of peer workers. A systematic review found that peer education interventions are associated with a three-fold increase in HIV testing with a consistent impact on behavioural change for over 24 months (15). Peers provide informational, emotional and affiliation support for utilization of testing services (16).

Discussions about communicable disease specifically and health status more broadly need to be considered in the context of social determinants of health. Inuit Tapiriit Kanatami has created Inuit-focused resources to inform organizations and government, including public health practice, on key social determinants of health for Canadian Inuit (2). In discussing health challenges faced by Inuit, researchers and others need to be mindful of the strength, richness and wealth of knowledge encompassed in Inuit culture. The impact of colonialism, including residential school programs, has been far-reaching and deeply impactful (17). The first government school for Inuit opened in Chesterfield Inlet in 1951. In June 1964, it is estimated that $75 \%$ of Inuit children and youth aged 6-15 years were enrolled in these schools as of 1964 and that at least 3,000 Inuit who attended residential schools are alive today. Westernization and colonization have been identified in the literature as negative influences on sexual health because of the loss of the accumulated wisdom and knowledge of Inuit regarding the life cycle, reproductive health and family planning, as well as traditional ways of life that incorporated both practical skills and cultural principles $(18,19)$. These have contributed to significant disruptions to family structures and relationships. Sexual abuse, including of children, is a significant concern. Organizations such as Pauktuutit have developed resources to try to support individuals and organizations in addressing this (20). In a recent survey of Inuit youth, most did not report using the Internet for sexual health information (18) but to quote one of the CHRs, social media often provides a "wrong message" about relationships. In the same survey, parents/caregivers were reported as the preferred sources of knowledge about sexual health and relationships among youth respondents. It was also noted that most households in Nunavut do not have internet 
access and only use public browsers that may inadvertently block sexual health content while intending to block pornographic content (18). In addition, social determinants of health, including inadequate, overcrowded housing and high unemployment rates, are closely connected to substance use in the territory (21). The substances most often used are alcohol and marijuana, and binge drinking is common. While little Canadian data are available, persons who use drugs are more likely to report stigma and mistrust of the healthcare system, which may contribute to decreased healthcare utilization and reluctance to identify and locate sex partners (22).

Community health representatives and other providers have commented on the importance of the choice of language when providing health services in Nunavut. Many health promotion programs in public health programs are developed by individuals whose first language is English. The majority of Nunavut residents identify Inuktitut as their first language. Language structure, vocabulary, sound systems, grammar and other considerations are important and affect meaning and communication. This is especially true when referring to health-related and sexual health concepts. Resources such as the "Tukisiviit: Do You Understand?" project with a sexual health glossary has been described as very helpful (23).

Small communities pose both benefits as well as challenges with the management of syphilis. Persons infected with syphilis may be concerned about the privacy of their health information in small communities and as such, may avoid coming to the local health centre where a relative may be working. In addition, access to medical services at most mines is limited which may result in a delay in diagnosis and treatment of cases and contacts. The remote nature of many communities results in a very long lag between specimen collection and the reporting of results. This can lead to ongoing transmission of the infection as well as disease progression. One of the ways that this delay could be mitigated is with POCT for the detection of syphilis. Currently there is no Health Canada approved point-of-care test (POCT) syphilis available. A Canadian Institutes of Health Research-funded initiative has commenced in Nunavut and Nunavik (a region comprising the northern third of the province of Québec) to evaluate the acceptability, performance and utility of a dual syphilis POCT (24); however, this work has been delayed due to the COVID-19 pandemic and staffing considerations. Improving the education of those at risk of acquiring the infection is also important and, at the request of the CHRs, work is underway to develop educational posters that include Inuktitut translations of text and visual displays of syphilitic lesions. We anticipate that this and other such education interventions will promote the utilization of sexually transmitted infection services in communities as similar peer-led initiatives have been successful in other settings (25-27). The utility of mobile health interventions, such as text message reminders for testing, has not been evaluated in Nunavut but such initiatives have been shown to increase syphilis and HIV testing, link persons to services and achieve behavioural change (28-32).

Ongoing work is needed to continue to improve community engagement, to deliver healthcare and public health services in a way as consistent with truth and reconciliation goals as possible, to incorporate more information on the CHRs and culturally-appropriate approaches to healthcare into the academic literature, and to end the current syphilis outbreak. Improved information on the experiences of individuals accessing healthcare and public health services is also needed.

\section{Conclusion}

Despite the logistical challenges with syphilis management in the territory, the overall outcomes have been positive, with no confirmed congenital cases identified. We attribute this to a coordinated effort by multiple partners including key actions by PHN and CHR.

\section{Authors' statement}
AS - Conceived of the report, drafted and revised the paper JP - Conceived of the report
$\mathrm{KK}$ - Analysed and interpreted the data

All authors reviewed drafts and contributed to revision of the manuscript.

The content and view expressed in this article are those of the authors and do not necessarily reflect those of the Government of Canada.

\section{Competing interests}

None.

\section{Acknowledgements}

We would like to acknowledge the invaluable role played by health providers delivering healthcare and public health services to Nunavummiut, both within the territory and elsewhere in Canada.

\section{Funding}

None. 


\section{References}

1. Nunavut Tunngavik Incorporated. Annual report on the state of Inuit culture and society, 2007-8. Iqaluit (NU): NTI; 2008 (accessed 2021-08-30). https://www.tunngavik.com/ publications/annual-report-on-the-state-of-inuit-culture-andsociety-2007-2008/

2. Inuit Tapiriit Kanatami. Comprehensive report on the social determinants of Inuit Health. Ottawa (ON): ITK; 2014 (accessed 2021-08-21). https://www.itk.ca/socialdeterminants-comprehensive-report/

3. Government of Nunavut. Nunavut Communicable Disease and Surveillance Manual. Section 6.4.1 Syphilis. Iqaluit (NU): Government of Nunavut; 2018 (accessed 2021-08-21). https://www.gov.nu.ca/documents/communicable-diseasemanual

4. Statistics Canada. Population estimates on July $1^{\text {st }}$, by age and sex (accessed 2022-01-26). https://www150.statcan. gc.ca/t1/tbl1/en/tv.action?pid=1710000501

5. Cherba M, Healey Akearok GK, MacDonald WA. Addressing provider turnover to improve health outcomes in Nunavut. CMAJ 2019;191(13):E361-4. DOI PubMed

6. Canadian Health Workforce Network. Comparative Review of Community Health Representatives Scope of Practice in International Indigenous Communities. NIICHRO; 2004. https://www.hhr-rhs.ca/index.php?option=com_ mtree\&task=viewlink\&link_id=7763\&lang=en

7. Pagaoa M, Grey J, Torrone E, Kreisel K, Stenger M, Weinstock $\mathrm{H}$. Trends in nationally notifiable sexually transmitted disease case reports during the US COVID-19 pandemic, January-December 2020. Sex Transm Dis 2021;48(10):798-804. DOI PubMed

8. Rac MW, Revell PA, Eppes CS. Syphilis during pregnancy: a preventable threat to maternal-fetal health. Am J Obstet Gynecol 2017;216(4):352-63. DOI PubMed

9. Poliquin V, Dhaliwal A, Lopez A, Bullard J. Local rate of Jarisch-Herxheimer reaction following penicillin treatment for syphilis during pregnancy. J Obstet Gynaecol Can 2020;42(5):689. DOI

10. Macumber $S$, Singh AE, Robinson J, Smyczek $P$, Sklar C, Gratix J, Rathjen L. Incidence and Outcomes of Jarisch-Herxheimer reactions following treatment for infectious syphilis in late pregnancy in Alberta Canada, 2015-2020. STI \& HIV World Congress. 2021;97 (Suppl 1):P438. https://sti.bmj.com/content/97/Suppl_1/ A173.1.abstract

11. Young TK, Tabish T, Young SK, Healey G. Patient transportation in Canada's northern territories: patterns, costs and providers' perspectives. Rural Remote Health 2019;19(2):5113. DOI PubMed

12. Hawkes SJ, Gomez GB, Broutet N. Early antenatal care: does it make a difference to outcomes of pregnancy associated with syphilis? A systematic review and meta-analysis.

PLoS One 2013;8(2):e56713. DOI PubMed
13. Zhang $X H, X u$ J, Chen DQ, Guo LF, Qiu LQ. Effectiveness of treatment to improve pregnancy outcomes among women with syphilis in Zhejiang Province, China. Sex Transm Infect 2016;92(7):537-41. DOl PubMed

14. Royal Commission on Aboriginal Peoples. Volume 3: Gathering Strength. Ottawa (ON): Canada Communications Group; 1996. https://data2.archives.ca/e/e448/e01118823003.pdf

15. He J, Wang Y, Du Z, Liao J, He N, Hao Y. Peer education for HIV prevention among high-risk groups: a systematic review and meta-analysis. BMC Infect Dis 2020;20(1):338. DOI PubMed

16. Dutcher MV, Phicil SN, Goldenkranz SB, Rajabiun S, Franks J, Loscher BS, Mabachi NM. "Positive Examples": a bottom-up approach to identifying best practices in HIV care and treatment based on the experiences of peer educators. AIDS Patient Care STDS 2011;25(7):403-11. DOI PubMed

17. Pauktuutit. Violence and Abuse Prevention: Residential Schools. Ottawa (ON): Pauktuutit (accessed 2021-08-15). https://www.pauktuutit.ca/abuse-prevention/children-andyouth/

18. Healey G. Youth perspectives on sexually transmitted infections and sexual health in Northern Canada and implications for public health practice. Int J Circumpolar Health 2016;75:1:30706. DOI

19. Healey GK, Meadows LM. Inuit women's health in Nunavut, Canada: a review of the literature. Int J Circumpolar Health 2007;66(3):199-214. DOI PubMed

20. Pauktuutit. Violence and Abuse Prevention: Children and Youth. Ottawa (ON): Pauktuutit (accessed 2021-09-01). https://www.pauktuutit.ca/abuse-prevention/children-andyouth/

21. Canada Drug Rehab. Nunavut Overview \& Quick Facts. Canada Drug Rehab (accessed 2021-08-21). https://www. canadadrugrehab.ca/nunavut/nunavut-overview-quick-facts/

22. Kidd SE, Grey JA, Torrone EA, Weinstock HS. Increased methamphetamine, injection drug and heroin use among women and heterosexual men with primary and secondary syphilis - United States, 2013-2017. MMWR Morb Mortal Wkly Rep 2019;68(6):144-8. DOI PubMed

23. Pauktuutit. Tukisiviit-Glossary. Ottawa (ON): Pauktuutit; 2014 (accessed 2021-09-01). https://www.pauktuutit.ca/health/ sexual-health/tukisiviit-glossary/

24. Canadian Institutes of Health Research. Stopping Syphilis Transmission in Arctic Communities through Rapid Diagnostic Testing (STAR study) (accessed 2021-08-27). https://webapps.cihr-irsc.gc.ca/decisions/p/project_details. html?applld=388947\&lang =en

25. Conserve DF, Jennings L, Aguiar C, Shin G, Handler L, Maman S. Systematic review of mobile health behavioural interventions to improve uptake of HIV testing for vulnerable and key populations. J Telemed Telecare 2017;23(2):347-59. DOI PubMed 
26. Burns $K$, Keating P, Free C. A systematic review of randomised control trials of sexual health interventions delivered by mobile technologies. BMC Public Health 2016;16(1):778. DOI PubMed

27. Beattie TS, Mohan HL, Bhattacharjee $P$, Chandrashekar S, Isac S, Wheeler T, Prakash R, Ramesh BM, Blanchard JF, Heise L, Vickerman P, Moses S, Watts C. Community mobilization and empowerment of female sex workers in Karnataka State, South India: associations with HIV and sexually transmitted infection risk. Am J Public Health 2014;104(8):1516-25. DOI PubMed

28. Paschen-Wolff MM, Restar A, Gandhi AD, Serafino $S$, Sandfort T. A systematic review of interventions that promote frequent HIV testing. AIDS Behav 2019;23(4):860-74. DOI PubMed

29. Santos VD, Costa AK, Lima IC, Alexandre HO, Gir E, Galvão MT. Use of the telephone for accessing people living with HIV/AIDS to antiretroviral therapy: systematic review. Cien Saude Colet 2019;24(9):3407-16. DOI PubMed
30. Geldof M, Thiombiano BA, Wagner N. "When I receive the message, it is a sign of love": symbolic connotations of SMS messages for people living with HIV in Burkina Faso. AIDS Care 2020;33(6):810-17. DOI PubMed

31. Wirsiy FS, Nsagha DS, Njajou OT, Besong JB. A protocol for a randomized controlled trial on mobile phone text messaging to improve sexo-reproductive health in Cameroon. J Public Health Epidemiol 2020;12(3):179-85. $\mathrm{DOI}$

32. Muhindo R, Mujugira A, Castelnuovo B, Sewankambo NK, Parkes-Ratanshi R, Kiguli J, Tumwesigye NM, Nakku-Joloba $E$. Text message reminders and peer education increase HIV and Syphilis testing among female sex workers: a pilot quasi-experimental study in Uganda. BMC Health Serv Res 2021;21(1):436. DOI PubMed

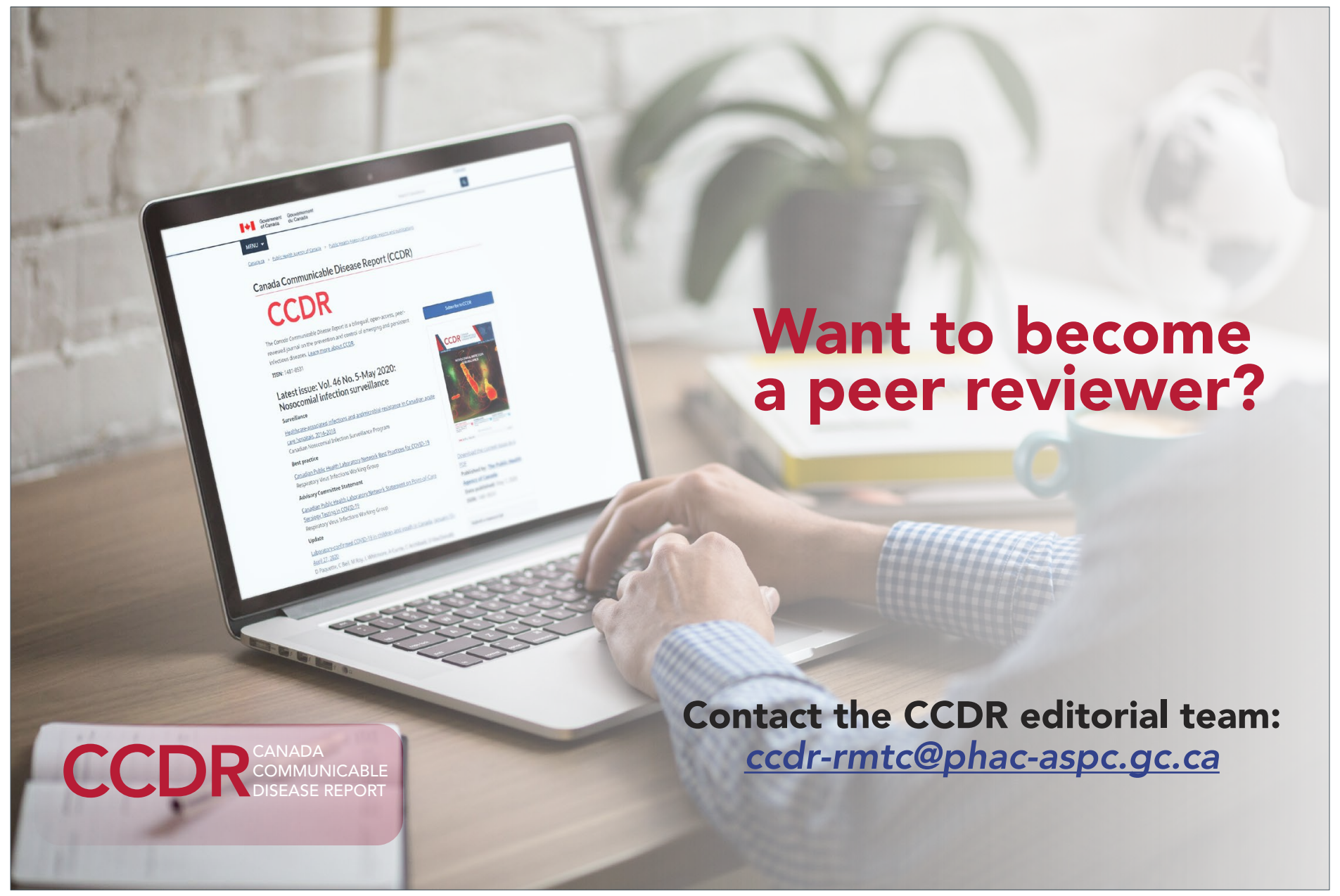

